\title{
Life Threatening Acute Heart Failure in Two Young Adults Treated with Antidepressant Medication
}

Inga Jóna Ingimarsdóttir ${ }^{1,2^{*}}$ and Gerhard Wikström ${ }^{1,2}$

${ }^{1}$ Institution of Medical Sciences, Uppsala University, Uppsala, Sweden

${ }^{2}$ Department of Cardiology, Uppsala University Hospital, Uppsala, Sweden

"Corresponding author: Inga Jóna Ingimarsdóttir, Institution of Medical Sciences, Uppsala University, Uppsala, Sweden, Tel: (+46)6110000; Fax: (+46)18551217; Email: inga.jona.ingimarsdottir@akademiska.se, ingajona@hotmail.com

Received date: September 23, 2014, Accepted date: November 21, 2014, Published date: November 28, 2014

Copyright: @ 2014 Ingimarsdóttir IJ, et al. This is an open-access article distributed under the terms of the Creative Commons Attribution License, which permits unrestricted use, distribution, and reproduction in any medium, provided the original author and source are credited.

\begin{abstract}
Duloxetine is a selective serotonin (5-HT) and norepinephrine reuptake inhibitor (SNRI) that is mainly prescribed for major depressive disorder and generalized anxiety disorder. It is our clinical experience that SNRI medication has caused severe heart failure in several patients, including one treated with Impella (LVAD).

Here we present two cases of young adults treated with Duloxetine who developed acute heart failure but had different outcomes.

Acute heart failure following treatment is not a registered side effect of SNRI medication. Our cases and other published case reports suggest that noradrenergic reuptake inhibitors like Duloxetine can cause catecholamine surges and result in reversible cardiomyopathies if no further complications occur.
\end{abstract}

Keywords: Acute heart failure; Antidepressants; Duloxetine; Left ventricular assist

\section{Introduction}

Duloxetine is a selective serotonin (5-HT) and norepinephrine reuptake inhibitor (SNRI). It is approved in the United States for major depressive disorder, generalized anxiety disorder, diabetic peripheral neuropathic pain, fibromyalgia, and chronic musculoskeletal pain. Its mechanism of action is by inhibiting the reuptake of serotonin and norepinephrine thereby increasing their concentrations in different locations in the central nervous system. It further causes a weak inhibition of the reuptake of dopamine with a negligible affinity for adrenergic, cholinergic, dopaminergic and histamine receptors. Stress cardiomyopathy has been reported after catecholamine administration [1], and has been associated to patients with pheochromocytoma $[2,3]$. One case report suggests that adrenergic medications like Duloxetine can cause catecholamine surges and result in reversible cardiomyopathies [4].

Acute left ventricular (LV) dysfunction, e.g. Takotsubo cardiomyopathy or stress cardiomyopathy, usually follows sudden emotional or physical stress [5]. The mechanism is believed to be mediated through epinephrine and causes stunning of the myocardium, with a predilection for the cardiac apex [6].

Current lists of side effects of Duloxetine do not enlist cardiomyopathy but do entail shortness of breath [7]. Patients treated with Duloxetine are not routinely followed for signs of heart failure.

\section{Methods}

Two individuals were admitted to our cardiology unit at Uppsala University Hospital with acute heart failure. The authors were clinically involved and responsible for the initial care and follow-up for both patients. Reports were reviewed and approved by the local Ethics Committee and both patients provided written consent forms for the publication.

\section{Case 1}

A 36-year-old female with a history of depression and anxiety disorder had been medicated with Duloxetine $60 \mathrm{mg}$ daily for 18 months and Mirtazapin for 6 months. For a period of six months she experienced increased lethargy and a $20 \mathrm{~kg}$ weight gain. Her symptoms were initially perceived as aggravated depressive symptoms.

At her local hospital she was diagnosed with dilated cardiomyopathy with a reduced left ventricular ejection fraction (LVEF) of 20-25\%. Her coronary angiography was normal. A cardiac MRI was inconclusive, i.e. had no definite sign of an earlier myocarditis. Her liver function tests (LFTs) were elevated. Heart failure management was initialized and she was planned for regular followup.

Two months later her heart failure symptoms progressed to NYHA class IV. She was dehydrated with increased creatinine $110 \mu \mathrm{mol} / \mathrm{L}$ (baseline $80 \mu \mathrm{mol} / \mathrm{L}$ ), hemoglobin was $140 \mathrm{~g} / \mathrm{L}$ (baseline $120 \mathrm{~g} / \mathrm{L}$ ), CRP $67 \mathrm{mg} / \mathrm{L}$ and NT-proBNP levels of $5800 \mathrm{ng} / \mathrm{L}$. Her LFTs were further elevated. Transthoracic echocardiography (TTE) showed a dilated left ventricle (LV) of $7 \mathrm{~cm}$, moderately dilated right ventricle (RV), a moderate to severe mitral insufficiency and severely reduced LV-EF of 10-15\%. Further, she had a thrombus located in the LV and an akinetic apex. Her systolic blood pressure was $80 \mathrm{mmHg}$ but was stabilized with inotropes and she also received Levosimendan. Duloxetine and Mirtazapine were terminated and she received Warfarin. She was referred to the cardiology unit at Uppsala University Hospital. 
Right heart catheterization (RHC) showed low pressures and low saturation in the pulmonary artery of approximately $40 \%$, a cardiac output of $2.4 \mathrm{~L} / \mathrm{min}$, a cardiac index of 1.1 and an AV02-difference of $89 \%$. She received Levosimendan again and received a Heart-Mate as a bridge to transplantation. Two months after the Heart-Mate operation her TTE showed LVEDD of $6.1 \mathrm{~cm}$, normal sized RV but she continued to have severely reduced LV-EF of $15 \%$ and wide-spread hypokinesia. Postoperatively PA-pressures increased and she was treated with Revatio. She is currently working half-time and is waiting for a heart transplant.

\section{Case 2}

A 40-year-old obese female with a history of hypertension, migraine, depression and chronic back pain had been taking Duloxetine $90 \mathrm{mg}$ daily for three years. For several months she had been under severe psychological stress because of a difficult domestic situation. Having been on benefits due to chronic back pain she was shortly before admission ordered to start a rehabilitation program, causing more stress. Further, she had been suffering from an upper respiratory tract infection for 3 weeks. Her other medications were Acetaminophen, Tramadol, Sumatriptan and Lactulose as needed.

She presented at the emergency room with sudden-onset heart failure, blood pressure 213/108 $\mathrm{mmHg}$, tachycardia and loss of consciousness. Electrocardiogram (ECG) showed a regular sinus rhythm of 145 beats per minute and a left bundle branch block (LBBB). Hearth sounds were normal but she had bilateral crackles over both lungs. A TTE showed a dilated right and left ventricle and universal dyskinesia with a LV-EF of 35\%. Laboratory tests showed BNP of approximately $1200 \mathrm{ng} / \mathrm{L}, \mathrm{CRP} 120 \mathrm{mg} / \mathrm{L}$, D-dimer of 12 and Troponin $764 \mathrm{ng} / \mathrm{L}$. Coronary angiography was normal. CT thorax showed bilateral pleural effusion, no pulmonary embolus but pneumonia could not be excluded.

She was connected to a ventilator. Her systolic blood pressure dropped to $60 \mathrm{mmHg}$ and she received low doses of Norepinephrine and Milrinone. She had intermittent VT attacks. Cardiac output measured by thermodilution was approximately $8 \mathrm{~L} / \mathrm{min}$ and Sv02 $80 \%$ and diuresis was normal.

Duloxetine was terminated on admission. She received a betablocker, an angiotensin receptor blocker and antibiotics. Five days later she was extubated and was fully alert. A new TTE revealed a normal LV-EF but she had a slight diastolic dysfunction with E/A of 0.9 and $\mathrm{E} / \mathrm{e}^{\prime}$ of 11. BNP returned to normal and she no longer had a LBBB. She is currently in NYHA class I and is working full-time.

\section{Discussion}

Duloxetine is believed to have the highest relative norepinephrine selectivity of the SNRI medications [8]. In recent years a handful of case reports have been published suggesting causation between SNRI medication and heart failure [9-11]. Fangio et al. reported a case of venlafaxine (another norepinephrine reuptake inhibitor) poisoning complicated by acute heart failure with reduced systolic function, elevation of NT-proBNP and hemodynamic instability in a previously healthy young adult. The cardiac function was fully restored in ten days after termination of the SNRI medication [11]. The same authors state that the findings in their case report share certain features of Takotsubo cardiomyopathy. Christoph et al. described a case of Takotsubo cardiomyopathy in a patient after an accidental overdose of Venlafaxine [10,11]. According to our clinical experience Venlafaxine has caused severe heart failure in several patients, including one treated with Impella (LVAD) [12].

Natural disasters have been shown to increase the incidence of stress cardiomyopathy [13]. Other types of physical illness, i.e. intracranial bleeding, can cause surges of sympathetic response resulting in acute ECG changes in around $10 \%$ of cases, elevated cardiac enzymes and acute but reversible LV impairment in the presence of normal coronary arteries [14,15]. A profound increase in plasma catecholamine levels has been reported in many cases following stress cardiomyopathy and they have been shown to be up to 34 times higher than normal resting values and significantly higher than with than among patients with ACS or heart failure [16,17].

When epinephrine circulates at physiological and elevated concentrations it triggers an intracellular signaling switch through $\beta 2$ adrenoceptors on cardiomyocytes of the ventricles causing a positive inotropic response. With high and long-standing (supraphysiological) epinephrine concentrations, however, they cause a negative inotropic effect on cardiomyocyte contraction [6]. This may cause myocardial apoptosis and heart failure because of LV dilatation [6]. One study has demonstrated that there is a higher concentration of $\beta$-adrenoceptors in the apical myocardium in canine hearts [18]. If it is similar in humans, it may account for the apical predilection observed in most cases. The human ventricular myocardium has a higher concentration of $\beta 2$-adrenoceptors than other mammals [19].

The use of norepinephrine reuptake inhibitors can increase the risk for heart failure with BNP elevation [16]. The apical wall motion abnormalities in stress cardiomyopathy are usually reversible within days or weeks of the acute insult (as is the case for traditional myocardial stunning) if no further complications occur [20]. A metaanalysis of forty-two placebo-controlled trials on individuals treated with Duloxetine showed a statistically significant increase in palpitations, tachycardia and hypertension [21].

Venlafaxine is mostly metabolized by the isoenzyme CYP2D6 and to a lesser extent by CYP3A4 [22]. Duoxetine is metabolized by CYP1A2 as well as CYP2D6. The pharmacokinetics of Duloxetine demonstates great interindividual variability (usually around 50-60\%) due to factors, e.g. sex, age, smoking status and ability to metabolize by means of the enzyme CYP2D6 [23]. For several pshychotropic drugs, the CYP2D6 isoenzyme is a high-affinity/low-capacity enzyme whose polymorphisms can phenotypically determine slow, extended, or rapid metabolization [24].

We have presented two case reports of young adults treated with Duloxetine that resulted in life threatening acute dilated cardiomyopathy with different outcomes. Case 1 had been treated for 18 months with no apparent increase in the amount of stressors. Case 2 had taken Duloxetine for three years. The question arises why the acute decompensated heart failure occurred after such prolonged treatment.

The level of stress in Case 1 was relatively stable. Ferreira et al. reported a similar case of a 35-year old female treated with Venlafaxine for 3 months that presented with reversible synchronous pneumonitis and acute cardiomyopathy attributed to Venlafaxine [25]. We do not know whether Case 1 had a CYP2D6 slow metabolizer genotype and can only hypothesize whether she had drug accumulation and subsequent cellular/organic insult, either due to drug accumulation or concomitant surges of cathecolamines. It is, however, an important fact that Duloxetine was not terminated until 
two months after Case 1 presented with heart failure symptoms. The delay may have caused the heart failure to be irreversible.

For Case 2 additional stressors were not present at the time she started the medication. Shortly before her decompensation she had found the additional stress to be extremely encumbering. We believe that the catecholamine surges caused by Duloxetine and increased stressors resulted in reversible cardiomyopathy. The cardiomyopathy, perhaps being a Takobsubo type, is reversible if no further complications occur.

There are certain shortcomings to this paper. We did not perform a twenty-four hour urine collection of cathecolamines. When we asked for titers of cathecolamines in the blood test of our patients the blood tests had been disposed of. We did not have information on the intake of other supplements that may have inhibited the P450 enzyme complex leading to drug accumulation.

\section{Conclusion}

We believe that Duloxetine played a central role in potentiating severe stresscardiomyopathy in both patients. We suggest that certain precautions with regular ECG's, BNP measurements and even annual TTE may be rationalized for patients treated with norepinephrine reuptake inhibitors. In case of heart failure symptoms we recommend that SNRI medication should be terminated.

\section{Authors Agreement}

No conflict to disclose.

\section{Funding}

None.

\section{References}

1. Abraham J, Mudd JO, Kapur NK, Klein K, Champion HC, et al. (2009) Stress cardiomyopathy after intravenous administration of catecholamines and beta-receptor agonists. J Am Coll Cardiol 53: 1320-1325.

2. Agarwal V, Kant G, Hans N, Messerli FH (2011) Takotsubo-like cardiomyopathy in pheochromocytoma. Int J Cardiol 153: 241-248.

3. Iga K, Gen H, Tomonaga G, Matsumura T, Hori K (1989) Reversible left ventricular wall motion impairment caused by pheochromocytoma--a case report. Jpn Circ J 53: 813-818.

4. Selke KJ, Dhar G, Cohn JM (2011) Takotsubo cardiomyopathy associated with titration of duloxetine. Tex Heart Inst J 38: 573-576.

5. Sealove BA, Tiyyagura S, Fuster V (2008) Takotsubo cardiomyopathy. J Gen Intern Med 23: 1904-1908.

6. Lyon AR, Rees PS, Prasad S, Poole-Wilson PA, Harding SE (2008) Stress (Takotsubo) cardiomyopathy - a novel pathophysiological hypothesis to explain catecholamine-induced acute myocardial stunning. Nat Clin Pract Cardiovasc Med 5: 22-29.
7. http://www.drugs.com/sfx/duloxetine-side-effects.html

8. Vaishnavi SN, Nemeroff CB, Plott SJ, Rao SG, Kranzler J, et al. (2004) Milnacipran: a comparative analysis of human monoamine uptake and transporter binding affinity. Biol Psychiatry 55: 320-322.

9. Charniot JC, Vignat N, Monsuez JJ, Kidouche R, Avramova B, et al. (2010) Cardiogenic shock associated with reversible dilated cardiomyopathy during therapy with regular doses of venlafaxine. Am J Emerg Med 28: 256.

10. Christoph M, Ebner B, Stolte D, Ibrahim K, Kolschmann S, et al. (2010) Broken heart syndrome: Tako Tsubo cardiomyopathy associated with an overdose of the serotonin-norepinephrine reuptake inhibitor Venlafaxine. Eur Neuropsychopharmacol 20: 594-597.

11. Fangio P, De Jonghe B, Appéré-De-Vecchi C, Lachérade JC, Terville JP, et al. (2007) Acute heart failure associated with venlafaxine poisoning. Am J Emerg Med 25: 210-211.

12. Wikström G, Kvidal P, Hagström E (2012) Life-threatening heart failure caused by ADHD medication. Five case reports described. Lakartidningen 109: 2016-2018.

13. Watanabe H, Kodama M, Okura Y, Aizawa Y, Tanabe N, et al. (2005) Impact of earthquakes on Takotsubo cardiomyopathy. JAMA 294: 305-307.

14. Kono T, Morita H, Kuroiwa T, Onaka H, Takatsuka H, et al. (1994) Left ventricular wall motion abnormalities in patients with subarachnoid hemorrhage: neurogenic stunned myocardium. J Am Coll Cardiol 24: 636-640.

15. Ennezat PV, Pesenti-Rossi D, Aubert JM, Rachenne V, Bauchart JJ, et al. (2005) Transient left ventricular basal dysfunction without coronary stenosis in acute cerebral disorders: a novel heart syndrome (inverted Takotsubo). Echocardiography 22: 599-602.

16. Wittstein IS, Thiemann DR, Lima JA, Baughman KL, Schulman SP, et al. (2005) Neurohumoral features of myocardial stunning due to sudden emotional stress. N Engl J Med 352: 539-548.

17. Goldstein DS, Eisenhofer G, Kopin IJ (2003) Sources and significance of plasma levels of catechols and their metabolites in humans. J Pharmacol Exp Ther 305: 800-811.

18. Mori H, Ishikawa S, Kojima S, Hayashi J, Watanabe Y, et al. (1993) Increased responsiveness of left ventricular apical myocardium to adrenergic stimuli. Cardiovasc Res 27: 192-198.

19. Port JD, Bristow MR (2001) Altered beta-adrenergic receptor gene regulation and signaling in chronic heart failure. J Mol Cell Cardiol 33: 887-905.

20. Akashi YJ, Nakazawa K, Sakakibara M, Miyake F, Koike H, et al. (2003) The clinical features of takotsubo cardiomyopathy. QJM 96: 563-573.

21. Wernicke J, Lledó A, Raskin J, Kajdasz DK, Wang F (2007) An evaluation of the cardiovascular safety profile of duloxetine: findings from 42 placebo-controlled studies. Drug Saf 30: 437-455.

22. Veefkind AH, Haffmans PM, Hoencamp E (2000) Venlafaxine serum levels and CYP2D6 genotype. Ther Drug Monit 22: 202-208.

23. http://www.fass.se/LIF/product?userType=2\&nplId=20040607005095

24. Eichelbaum M, Evert B (1996) Influence of pharmacogenetics on drug disposition and response. Clin Exp Pharmacol Physiol 23: 983-985.

25. Ferreira PG, Costa S, Dias N, Ferreira AJ, Franco F (2014) Simultaneous interstitial pneumonitis and cardiomyopathy induced by venlafaxine. J Bras Pneumol 40: 313-318. 